\title{
DEVELOPMENT OF A MACHINE FOR CUTTING SUGAR CANE BUDS
}

\section{Wael A. Mahmoud ${ }^{1}$ and Ashour E. Abu El-maaty ${ }^{1 \&^{*}}$}

${ }^{1}$ Assist. Prof., Fac. of Ag. Eng., Al-Azhar U., Assiut Branch, Egypt.

* E-mail: AshourEid.50@azhar.edu.eg

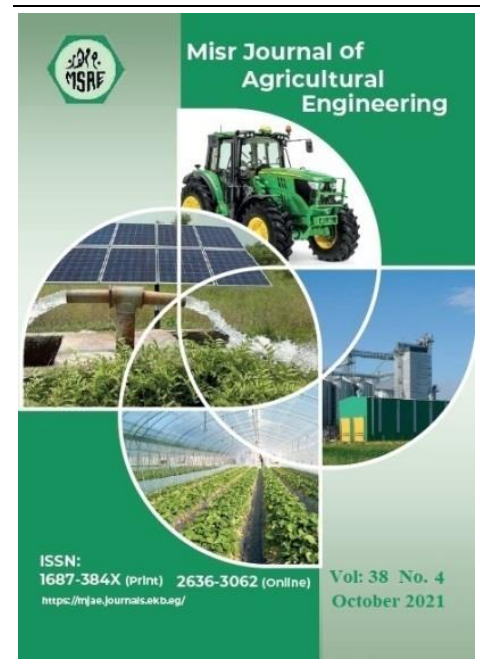

(ㄱ Misr J. Ag. Eng. (MJAE)

\section{Keywords:}

Cutting buds machine;

Sugar cane buds; Cutting

efficiency; Machine

productivity

\begin{abstract}
This research aims to manufacture and test a machine for cutting sugar cane buds to develop mechanization of the stage of preparing sugarcane seedlings in the nursery. The developed machine consists of a frame, cutting unite, electric motor, and power transmission system. This machine will save the time, effort and costs spent on cutting reeds by traditional methods at farmers. The machine cuts the sugarcane stalks that are used as seeds and which contain undamaged buds, the operator cuts the groups of sprouts by the bud cutting machine. The machine has been tested at three transmission ratios to cutting rate of $R_{1}=$ $22, R_{2}=32$, and $R_{3}=40 \mathrm{buds} / \mathrm{min}$. The results of preliminary tests revealed that the machine achieved the skipping, percentage of damaged, cutting efficiency, and productivity was (4.09, 7.19, 11\%), (2.37, 5.39, and 8.99\%), (97.63, 94.61, 91\%), $\left(1266,1782,2136 \mathrm{bud} / \mathrm{hr}\right.$.) at the cutting rate $R_{1}, R_{2}$, and $R_{3}$ respectively. The total costs for operating the machine are 50.3 L.E./h to at the highest cutting rate $R_{3}$.
\end{abstract}

\section{INTRODUCTION}

$\mathrm{S}$ ugar cane (Saccharum officinarum L.) is considered the main source of sugar production in Egypt and many countries around the world. The area of sugar cane in Egypt reached up to 332 thousand feddan, with an average production of $48.6 \mathrm{Mg} / \mathrm{fed}$., (CCSC, 2020). The transplanting technique has been applied in several countries for reducing the duration of the sugarcane production season. Sugarcane seedling planting in the nursery is done using the single buds, the sugarcane buds it means excised axillary buds from cane stalk, these buds are less in size, easily transportable, fast-growing, and more economical seed material. Traditional hand-held cutting tools of sugarcane buds create a strain on the hands and thumb, cause wastage, and damage with slanting cuts, and are incapable of dealing with hard plant grafting. Sugarcane transplanting has been recommended as an alternative planting method for saving a considerable part of irrigation water that determines the expansion of the agricultural areas in the country. (Drees, 2005) recommended that sugarcane transplanting could be used as an alternative method of the sugarcane seedlings. The application of the transplanting technique to replace traditional planting of sugarcane saves up two months of the crop production season. (Mahmoud, 2016) mentioned the feddan $\left(4200 \mathrm{~m}^{2}\right)$ is needed about $1600 \mathrm{~kg}$ from sugar cane stalks suitable for agriculture for obtaining bud sets. (Abd El 
Mawla, et al., 2014) reported that the transplanting sugarcane saves a considerable amount of irrigation water determined as $2000 \mathrm{~m}^{3} /$ acre and the quantity of seed consumed when applying the transplanting technique is largely less than that of the traditional method. (Ragupathi et al., 2017) said that the traditional tools used for bud chipping of sugar cane are unsafe, messy, minimum productive, and need skill and training, the risk of injury is also too high, this necessitates the development of an automated sugarcane bud chipping machine. (Suraj et. al., 2016) designed and fabricated of a pedal operated sugarcane bud chipping machine where the sugarcane is fed to the cutting region manually, when the operator starts pedaling the cutting action starts and the sugarcane buds are cut along with the stalk. (ElNakib et al., 1996) performed tests on the Egyptian sugar cane variety C-9 and they found that the average diameter of the stalk was $2.3 \mathrm{~cm}$, and the cane stalk hardness was $775 \mathrm{~N}$. (Abarna et al., 2017) designed machine cutting buds from sugarcane stalk consists of a platform, hemisphere chipping knife, sphere chipping knife, linkage system, and handle, it is used to chip out the bud from sugarcane for sowing purpose and for tissue culture that, this machine can remove buds from the sugarcane for the plantation purpose to minimize losses as well as time, money, and seeds, with this implement. (Mahesh et al., 2017) mentioned that the bud chip technology could be one of the most viable and economical alternatives for a manually operated machine and can be converted manually operated machines into automatic ones by using an electric motor. (Rahul A. et al., 2017) developed a machine is semiautomatic with pedal-operated to the sugarcane is cut in curve shape, where the only bud is cut, therefore remaining sugarcane is reuse.

The main objective of this research is the development and performance evaluation of a machine for cutting sugar cane buds to increase the efficiency of the buds cutting process, reduce the muscular effort exerted by the laborers, and replacing the manual method of cutting buds with semi- Automatic.

\section{MATERIAL AND METHODS}

The prototype of the cutting buds machine was constructed in the workshop of the Faculty of Agricultural Engineering, Al-Azhar University, Assiut. All the experiments were carried out during November 2020. to study the possibility development of mechanical cutting to stem sugarcane buds and used in planting instead of using full lengths of sugarcane.

\subsection{Sugarcane stalks characteristics.}

The source of the sugarcane stalks used in this research was from the Sugarcane crops Research Institute, ARC, Egypt, Sohag, Shandawill (شندويل). The samples were selected, cleaned, and shelled manually. The measurements and tests were carried out in the Fac. of Agri. Eng., Al-Azhar U., Assiut. Characteristics of sugarcane C-9 variety stalk before buds separation to use for obtaining of buds are presented in Table (1), the obtained data is approximately compatible with (Mahmoud, 2016):

\subsection{Sugarcane buds cutting machine.}

\section{Frame of the machine:}

The frame was fabricated from square welded iron sections $50 \times 50 \mathrm{~mm}$, thickness $3 \mathrm{~mm}$. The frame shape was formed with certain dimensions $500 \mathrm{~mm}$ width, $900 \mathrm{~mm}$ length, and $900 \mathrm{~mm}$ 
height. To mount various components of the machine such as power transmission system, cutting unite, electric motor $(1400 \mathrm{rpm})$, and other components. The components of the sugarcane buds cutting machine are shown in Fig. (1).

Table (1): Average characteristics of sugarcane C-9 variety stalk before buds separation:

\begin{tabular}{|l|c|c|}
\hline \multicolumn{1}{|c|}{ Characteristics } & Averages & \pm S.D $^{*}$ \\
\hline Stalk length "L" cm. & 295.3 & \pm 9.13 \\
\hline Stalk diameter "D" cm. & 2.35 & \pm 0.15 \\
\hline Stalk mass "M" kg. & 1.97 & \pm 0.11 \\
\hline Number of buds on the stalk. & 16.33 & \pm 1.80 \\
\hline
\end{tabular}

${ }^{*}$ S.D. is the standard deviation.

\section{Cutting unite.}

The cutting unite consists of as shown in Fig. (2) a plunger, eccentric wheel, and connecting rod. plunger made of square shaft of $30 \mathrm{~mm}$ and length of $320 \mathrm{~mm}$. The eccentric wheel is made of iron with a diameter of $200 \mathrm{~mm}$ and a thickness of $10 \mathrm{~mm}$. the connecting rod is made of an iron plate with dimensions of $180 \mathrm{~mm}$ in length, $20 \mathrm{~mm}$ width, and $10 \mathrm{~mm}$ in thickness. The connecting rod is connected with the plunger and eccentric wheel by two hinges.

\section{Cutting Blade.}

The cutting blade consists of two knives from stainless steel with dimensions are $(100 \times 20 \times$ $3 \mathrm{~mm}$ ) and parallels, the distance between them is the length of $50 \mathrm{~mm}$.

The knife was used with three cutting angles 15, 30, 45 degrees, the knife was sharpened by the laser iron cutting machine.
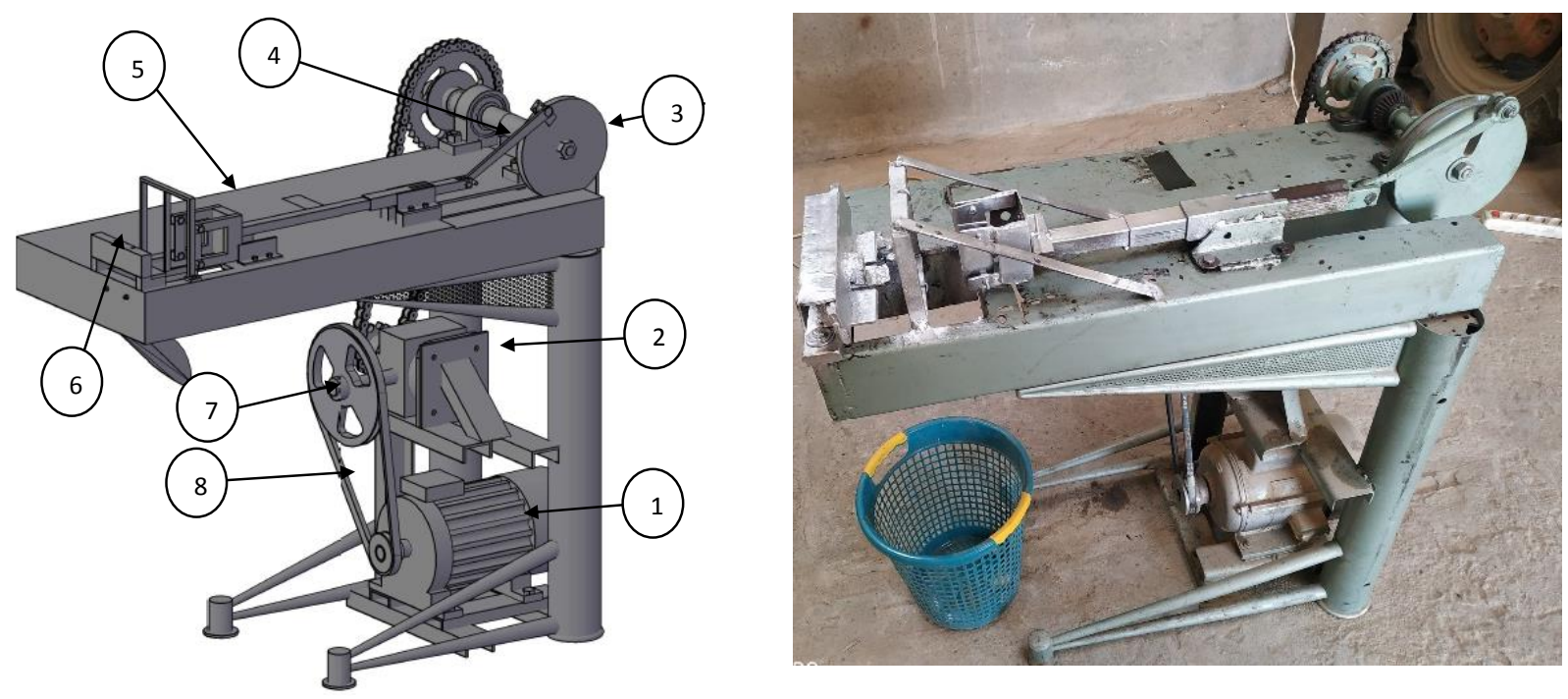

1. Electric motor

2. Gearbox.

3. Eccentric wheel.

4. Connected rod.

5. Cutting Blade.

6. Barrier.

7. Pulley.

8. V-Belt.

Fig. 1: The sugarcane bud cutting machine. 

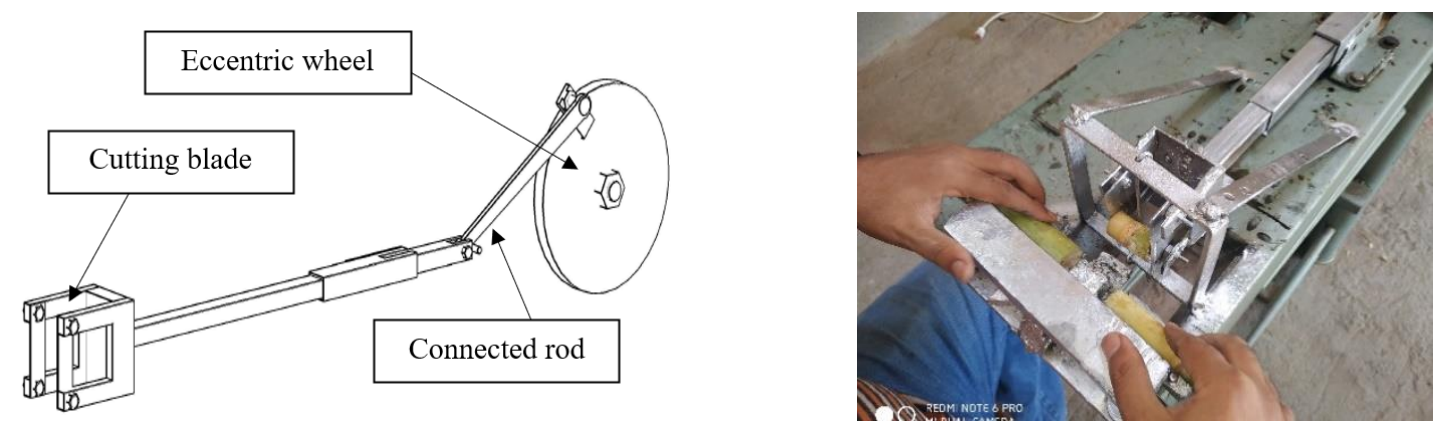

Fig. 2: The cutting unit.

\section{Transmission system.}

The power transmission of the cutting buds machine is shown in Fig. (3). The power is transmitted from the electric motor $1400 \mathrm{rpm}$ to the cutting unit by a gearbox with a speed ratio of $35: 1$, by two pulleys, diameters of the pulley $(1)=14,12$ and $15 \mathrm{~cm}$ on the motor shaft, and diameters of the pulley (2) $=12$ and $7 \mathrm{~cm}$ on the gearbox shaft. The different diameters were used to obtain the variable for a cutting rate of $R_{1}=22, R_{2}=32$ and $R_{3}=40$ buds/min. as shown in Table (2). The power is transmitted from the gearbox to the cutting unit by two sprockets (15 and 32 teeth) and a chine.

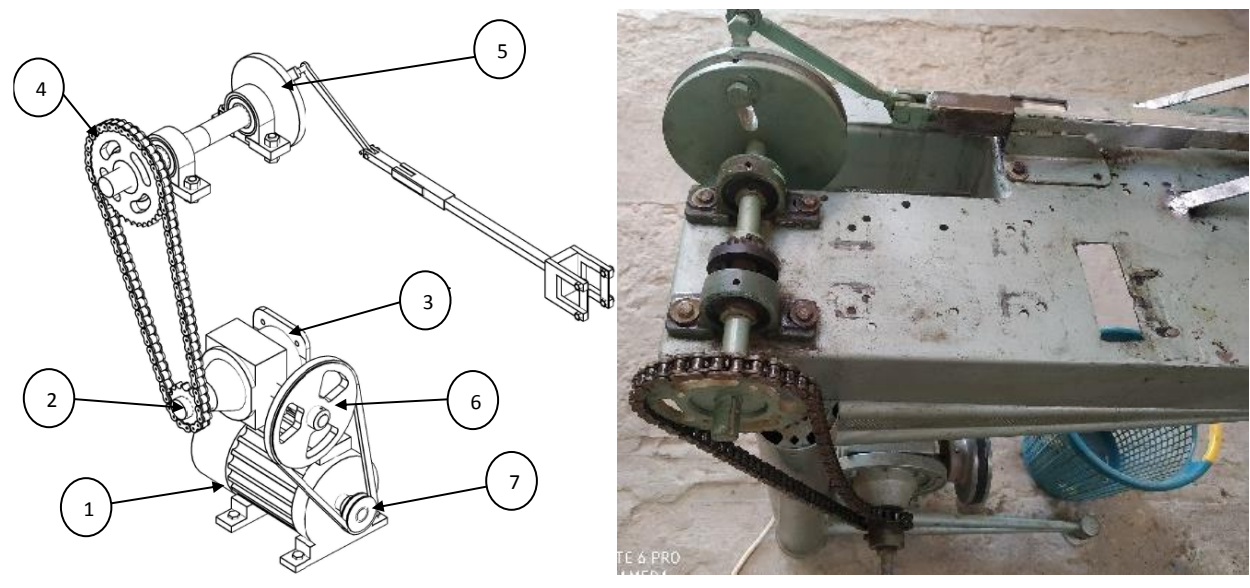
1. Electric motor
2. Gearbox.
3. Sprocket 15 Teeth.
4. Sprocket, 32 Teeth.
5. Eccentric wheel
6. Pulley (2).
7. Pulley of motor (1).
8. V-Belt.

Fig. 3: Detailed descriptions of the power transmission system.

Table 2: The power transmission.

\begin{tabular}{|c|c|c|c|}
\hline \multirow{2}{*}{ Number of transmission tools. } & \multicolumn{3}{|c|}{ Cutting rate, bud/min. } \\
\cline { 2 - 4 } & $\mathrm{R} 1$ & $\mathrm{R} 2$ & $\mathrm{R} 3$ \\
\hline Diameters of pulley (1), mm. & 140 & 120 & 150 \\
\hline Diameters of pulley (2), mm. & 120 & 70 & 70 \\
\hline Rotation speed of pulley (1), rpm. & 1400 & 1400 & 1400 \\
\hline Input gear box, rpm. & 1633 & 2400 & 3000 \\
\hline Output gear box (on sprocket 15 teeth), rpm. & 46.7 & 68.6 & 85.7 \\
\hline Sprocket 32 teeth, rpm. & 22 & 32 & 40 \\
\hline Eccentric wheel, rpm. & 22 & 32 & 40 \\
\hline
\end{tabular}




\section{Power and torque calculations.}

The force required to cut the sugarcane bud is $697.2 \mathrm{~N}$. from two blades. according to (Ali, 2012):

$\mathrm{T}=F \times r$

Where:

$\mathrm{T}=$ Torque in N.m

$\mathrm{F}=$ the force required to cut the sugarcane bud.

$\mathrm{T}=697.2 \times 0.08=55.78 \mathrm{~N} . \mathrm{m}$

$\mathrm{P}=\frac{2 \pi N T}{60}, \ldots \ldots . . \mathrm{Watt}$.

Where:

$\mathrm{P}=$ Power of motor in Watt.

$\mathrm{T}=$ Torque in N.m

$\mathrm{N}=$ Speed of motor in rpm.

$\mathrm{P}=\frac{2 \times 3.14 \times 22 \times 55.78}{60}=128.44 \mathrm{~W}$.

It is clear from the previous equations that the required power when using speeds $(22,32$, and $40 \mathrm{rpm})$ was $(128.36,186.83$, and $233.53 \mathrm{~W})$, respectively.

\section{Electrical motor:}

Based on the maximum mathematical power obtained $(233.53 \mathrm{~W})$ was chosen the electric motor of $0.75 \mathrm{~kW}(1 \mathrm{hp}), 89 \%$ effective load, and $1400 \mathrm{rpm}$ (obtained from the nameplate), was used to move the cutting unit by the transmission system.

\subsection{Process of bud cutting and preparation.}

By used mature sugarcane stalks which using as seeds and that contain undamaged buds, the operator is cutting sets bud by cutting buds machine shown in Fig. 1.

The cutting machine produces equal sets in the length and contents one a bud and can be controlled in sets length (from $3 \mathrm{~cm}$ to $5 \mathrm{~cm}$ ) by adjusting the distance between the pair cutting knife.

The products of cane buds cut fall down the machine into the allocated receptacle. The cutting products fall out of the machine as classified to:

- Sets with undamaged buds.

- Sets with damaged buds.

- Sets of internodes with no buds.

\subsection{Measurements:}

The developed prototype of the cutting buds machine was tested considering the measurements related to prototype performance to realize the purpose of this research. Measurements as following:

\section{Actual number of buds per minutes ( $\mathrm{Nb}$ actual).}

The actual number of buds that can be cut during feeding by the operator compared to the number of cuts calculated by the theoretical cutting rate (N. $\left.b_{\text {theo }}\right)$. 


\section{Skipping rate $(\mathrm{Sr}, \%)$.}

Skip rate refers to the number of cuts of the cutting knife without feeding by the operator which usually results from increasing the reciprocating speed of the cutting knife. Skip rate is useful for determining the optimum reciprocating speed of the cutting knife it can be calculated as a percentage of the number of skipped cuts divided by the theoretical number of cutting knife frequencies with each speed.

$\operatorname{Sr}, \%=\frac{N b_{T h e o}-N b_{a c t u}}{N b_{\text {theo }}} \times 100$

Where:

$N b_{\text {Theo }}=$ Number of theoretical cutting rate $(\mathrm{bud} / \mathrm{min}$.

$N b_{a c t u}=$ Number of actual cutting buds $(\mathrm{bud} / \mathrm{min})$.

\section{The percentage of damaged buds (Nbd, \%).}

The damaged bud means mechanical damage to the bud scar due to the cutting process. decrease in the number of damaged buds indicates an increase in the percentage of cutting efficiency. The percentage of the damage was calculated by counting the damaged buds and relative to the actual number of buds that had been cut.

$N b d=\frac{N b d}{N b_{a c t u}}$

Where:

$N b d=$ Number of damaged buds.

\section{Cutting efficiency $(\eta c, \%)$.}

Cutting efficiency refers to the number of healthy cut buds relative to the total actual number of cut buds.

$\eta c, \%=\frac{N b_{a c t u}-N b d}{N b_{a c t u}}$

Where:

$\eta c=$ Cutting efficiency

\section{Classification damage of cutting-edge buds:}

The cutting-edge damage buds were inspected and classified according to the degree of damage following the classification of Kroes (1997). Fig. (4) show Kroes's classification of damage.

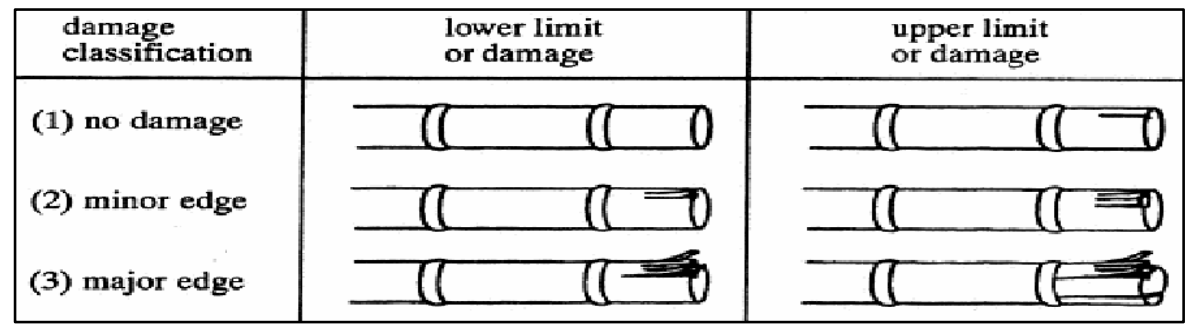

Fig. 4: Classification of sugarcane damage according to (kroes, 1997) 


\section{Machine productivity $(\mathrm{Q}, \mathrm{Nb} / \mathrm{h})$.}

Machine productivity was estimated by using the following equation:

$\mathrm{Q}=\frac{\mathrm{Nb}_{\text {actual }}}{t}$.

Where: $\mathrm{Nb}_{\text {actual }}=$ Actual number of buds per minutes at time $\mathrm{t}$, (h).

\subsection{Operation costs.}

Cost of operation was calculated according to the equation given by Awady (1978), in the following form:

$\mathrm{C}=\mathrm{P} / \mathrm{h}(1 / \mathrm{a}+\mathrm{I} / 2+\mathrm{t}+\mathrm{r})+(\mathrm{w} \cdot \mathrm{e})+\mathrm{m} / 144$.

Where: $\mathrm{C}=$ hourly cost, $\mathrm{LE} / \mathrm{h}, \mathrm{P}=$ price of machine, $(6000 \mathrm{LE}), \mathrm{h}=$ yearly working hours $(1000 \mathrm{~h}), \mathrm{a}=$ life expectancy of the machine $(10$ year $), \mathrm{i}=$ interest rate/year $(9.75), \mathrm{t}=$ taxes $(0.20), r=$ overheads and indirect cost ratio (0.06), $\mathrm{w}=$ electrical power consumed to charge the battery, $\mathrm{kW}, \mathrm{e}=$ electrical price, and $\mathrm{m}=$ monthly wage rate. "1.2" is a factor (upper limit) to take lubrication and greasing into account. "144" is estimated monthly working hours. Notice that all units must be consistent to result in L.E/h.

\section{RESULTS AND DISCUSSION}

The working idea of the developed prototype of the cutting buds machine is based on cutting buds of sugarcane stalks through the clearance between the two cutting knives, which moves a horizontal reciprocating motion. Consequently, cut shoots can fall off through the blank under the cutting unit. The bud chips or short sets that include one bud by cutting machine were developed, which used to establish the sugarcane seedlings nursery were prepared where each bud chip includes a healthy bud and root band.

\section{Effect of cutting rate on the skipping rate $\left(\mathrm{S}_{\mathrm{r}}, \%\right)$.}

The cutting rate of the cutting unit determines the number of buds that can be cut per minute determine the optimum feeding speed by the operator. The rate of skipping the cutting unit and not utilizing it in cutting the buds is due to the increased reciprocating speed for the cutting unit. During the initial stages of selecting the transmission ratio, the theoretical rate of cutting buds was $\mathrm{R}_{1}=22$ buds per minute and it was found through experiments that there the skipping rate was $4.09 \%$. While the percentage of skipping rate was $7.19 \%$ at the theoretical rate of cutting buds $\mathrm{R}_{2}=32$ buds per minute and the percentage of skipping rate was $11.00 \%$ at the theoretical rate of cutting buds $R_{3}=40$ buds per minute as shown in Table 3 and Fig. (5).

Table 3: Effect of cutting rate on the skipping rate ( $\mathrm{Sr}$ ), No. of damage buds (Nb.d), Cutting efficiency $\left(\eta_{\mathrm{c}}\right), \%$ and Productivity, bud/hr.

\begin{tabular}{|c|c|c|c|c|c|}
\hline \multicolumn{2}{|c|}{ Cutting rate, bud/min. } & \multirow{2}{*}{$\begin{array}{l}\text { Ave. Perce. } \\
\text { of skipping } \\
\text { rate }(\mathrm{Sr}, \%) .\end{array}$} & \multirow{2}{*}{$\begin{array}{l}\text { Ave. Perce. of } \\
\text { damage buds } \\
(\mathrm{Nbd}, \%)\end{array}$} & \multirow{2}{*}{$\begin{array}{l}\text { Cutting } \\
\text { efficiency } \\
(\eta \mathrm{c}), \%\end{array}$} & \multirow{2}{*}{$\begin{array}{l}\text { Productivity } \\
\text { bud/hr. }\end{array}$} \\
\hline$\left(N . b_{\text {theo }}\right)^{*}$ & $\begin{array}{l}\text { Ave. } \\
\left(\boldsymbol{N} . \boldsymbol{b}_{\text {actu. }}\right)^{* *}\end{array}$ & & & & \\
\hline $\mathrm{R}_{1}=22$ & 21.5 & 4.09 & 2.37 & 97.63 & 1266 \\
\hline $\mathrm{R}_{2}=32$ & 29.7 & 7.19 & 5.39 & 94.61 & 1782 \\
\hline $\mathrm{R}_{3}=40$ & 35.6 & 11 & 8.99 & 91.01 & 2136 \\
\hline
\end{tabular}

* Theo. No. of bud per minutes. **Actu. No. of bud per minutes. 


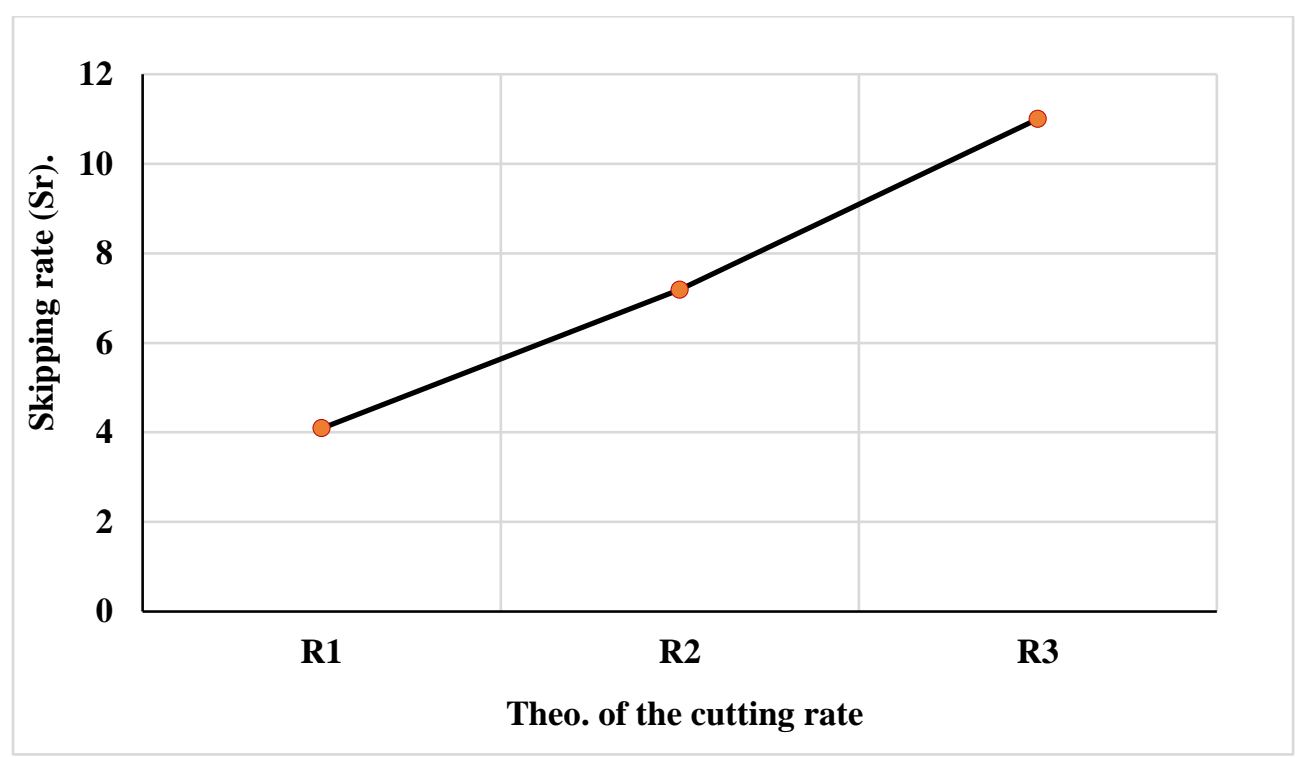

Fig. 5: Effect of cutting rate on the skipping rate $(\mathrm{Sr}, \%)$.

\section{Effect of cutting rate on the percentage of damaged buds (Nbd, \%).}

Mechanical damage to the buds may occur by the cutting knife due to the wrong feeding from the laborer, by the higher the reciprocating speed of the cutting knife, increased the percentage of damaged buds. Fig. (6) shows that by increasing cutting rate $R_{1}, R_{2}$, and $R_{3}$ increased to percentage of damaged buds. When increase of cutting rate from $R_{1}, R_{2}$, and $R_{3}$ increased of percentage of damaged from $2.37,5.39$, and $8.99 \%$ respectively.

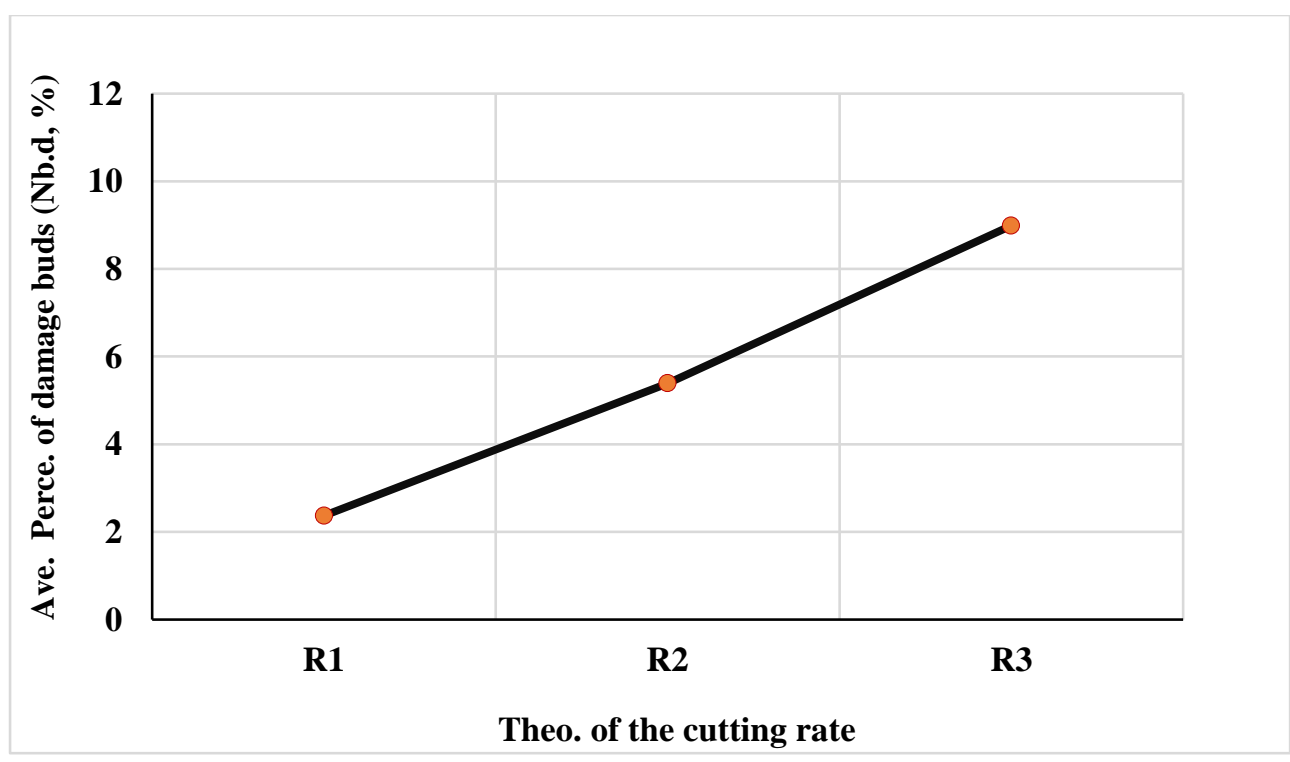

Fig. 6: Effect of the cutting rate on the percentage of damaged buds (Nbd, \%).

\section{Classification damage of cutting-edge buds:}

Fig. (7) shows that increasing cutting rate $\mathrm{R}_{1}, \mathrm{R}_{2}$, and $\mathrm{R}_{3}$ decreased the classification of damage (No damage) from 93.49, 92.95 and $86.28 \%, 96.52,94.84$ and 93.88 and $98.27 \%$, 95.27 and $94.15 \%$ at cutting angles of knife 15, 30, and 45 degrees, respectively. While increasing the classification of damage (minor edge) from 4.57, 5.04 and10.08 \%, 2.47, 3.70 and 4.55 and 1.08, 3.60 and $4.78 \%$ at cutting angles of knife 15, 30, and 45 degrees, respectively. 


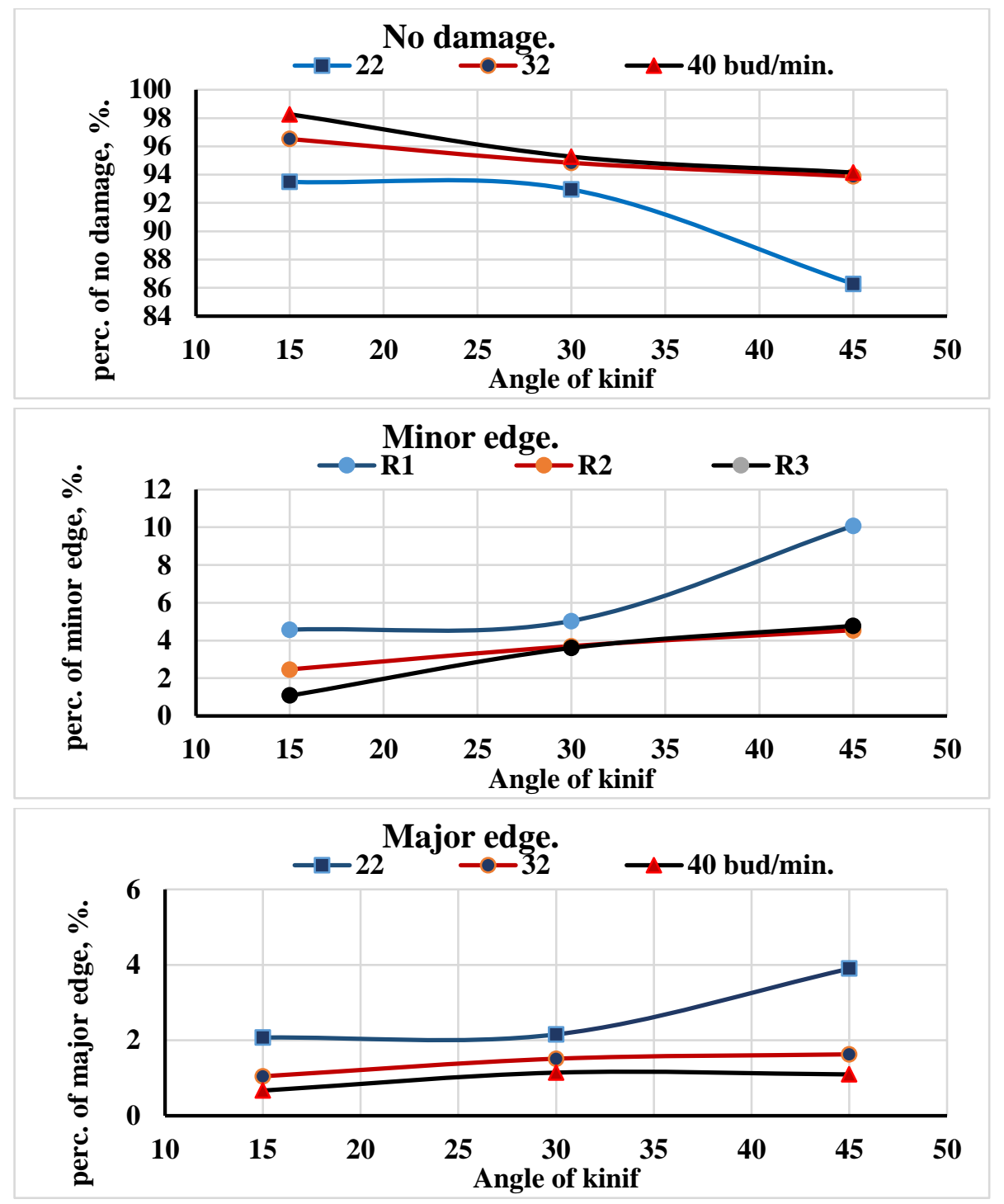

Fig. 7: Effect of the cutting rate on damage classification of the buds.

And increased the classification of damage (minor edge) from 2.07, 2.16, and $3.90 \%, 1.05$, 1.51 and 1.63 and 0.67 and 1.14 and $1.10 \%$ at cutting angles of knife 15, 30, and 45 degrees, respectively. The classification damage of cutting-edge was calculated for buds according to actual productivity.

\section{Effect of cutting rate on cutting efficiency ( $\eta \mathrm{c}, \%)$.}

Table (3) and Fig. (8) illustrate decreasing of the cutting efficiency with increasing of the theoretical cutting rate. The highest of cutting efficiency was $97.63 \%$ when the theoretical cutting rate 22 buds/min., and lowest of cutting efficiency was $91.01 \%$ when the theoretical cutting rate 40 buds/min.

\section{Effect of cutting rate on the productivity $(\mathrm{Q}, \mathrm{Nb} / \mathrm{h})$.}

Table (3) and Fig. (9) shown that the lowest productivity was $1266 \mathrm{Nb} / \mathrm{h}$ when using a cutting rate $\mathrm{R}_{1}$, while the highest productivity was $2136 \mathrm{Nb} / \mathrm{h}$ when using a cutting rate $\mathrm{R}_{3}$.

\section{Cost estimation:}

Production cost was calculated by the maximum value of the machine productivity 2136 $\mathrm{bud} / \mathrm{h}$ that it was obtained with the maximum value of the power required. Accordingly, the maximum operation production cost will be 50.3 L.E./h. 


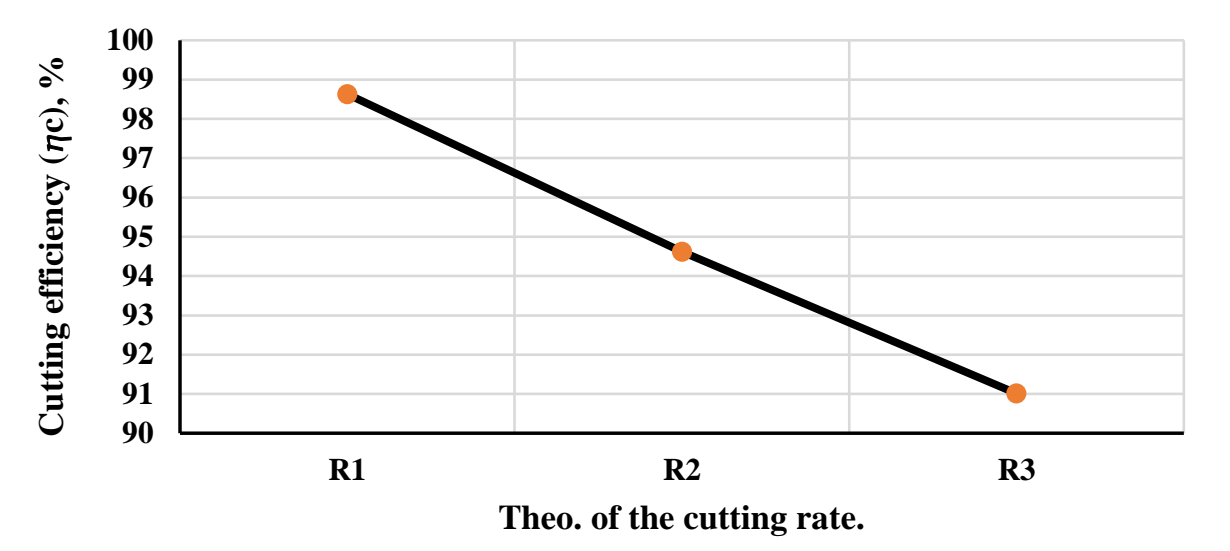

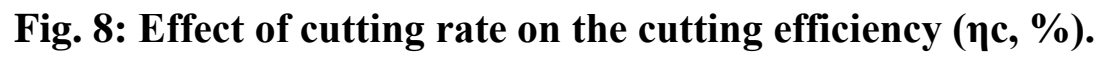

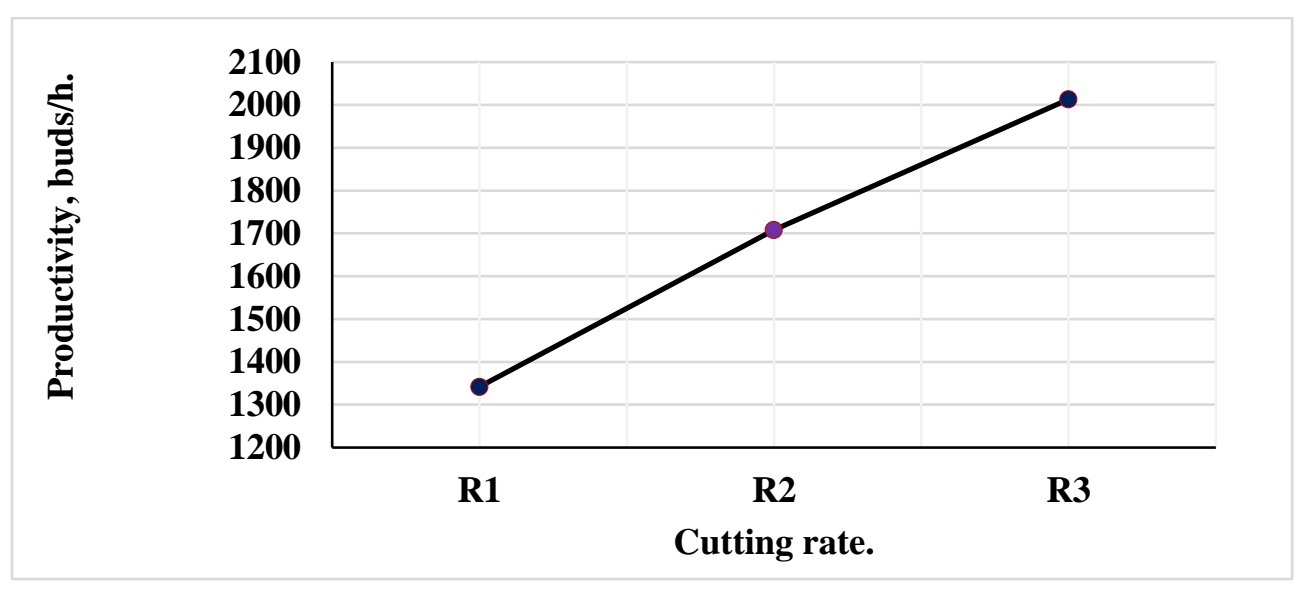

Fig. 9: Effect of cutting rate on the productivity $(\mathrm{Q}, \mathrm{Nb} / \mathrm{h})$.

\section{CONCLUSION.}

Overall results of this applied research may be concluded as follow:

1- Design a prototype for sugarcane buds cutting machine to develop mechanization of the stage of preparing sugarcane seedlings in the nursery. The machine is characterized by a simple design and local materials, that can be manufactured in rural workshops. This machine will save the time, effort and costs spent on cutting reeds by traditional methods at farmers.

2- Using lower cutting rate $\mathrm{R}_{1}$ given cutting rate theoretical of cutting buds was 22 buds per minutes, the skipping rate was $4.09 \%$, while the highest skipping rate was $11 \%$ using cutting rate $\mathrm{R}_{3}$ which the theoretical rate of cutting buds was 40 buds per minutes.

3- By increasing the cutting rate from $\mathrm{R} 1, \mathrm{R} 2$, to $\mathrm{R} 3$ increased the percentage of damaged buds from $2.37,5.39$, to $8.99 \%$ respectively.

4- Highest cutting efficiency was $97.63 \%$ when cutting rate $\mathrm{R}_{1}$ and the lowest of cutting efficiency was $91 \%$ when cutting rate $\mathrm{R}_{3}$.

5- The highest productivity was $2136 \mathrm{bud} / \mathrm{h}$. when using a cutting rate $\mathrm{R}_{3}$, while the lowest productivity was $1266 \mathrm{bud} / \mathrm{h}$. when using a cutting rate $\mathrm{R}_{1}$.

6- The total costs for the machine operation are 50.3 L.E./h. to the maximum value of the machine productivity $2136 \mathrm{bud} / \mathrm{h}$ at cutting rate $\mathrm{R}_{3}$. 


\section{REFERENCES.}

Abarna. R., M. Dhayanethi, A.S. Elango, M. Elango, and R. Hari Prasanth (2017). Fabrication of sugarcane bud removal machine with advancements. International Journal of Innovation and Scientific Research. Vol. 30 No. 3 May 2017, Page: 501-506.

Abd El Mawla. H. A., B. Hemida, W. A. Mahmoud, (2014). Study on the mechanization of sugarcane transplanting. International Journal of Engineering and Technical Research. Vol. 2, Issue 8. Page: 237-241.

Ali. M. H., (2011). Development of a single row harvester for sugarcane. Ph.D. Thesis, Fac. of Agric., Al-Azhar Univ., Cairo, (Egypt). Page: 44.

Awady, M. N., 1978, Tractors and farm machines, in Arabic, text. Col. Ag., A. Shams U.: 164-167.

CCSC (Central Council for Sugar Crops), (2020). World status of sugar crops, productivity of sugar crops in Egypt. Sugar crops and sugar production in Egypt and the world. Ministry of Agriculture. Page: 1:85.

Drees, A. M. (2005). “A study on mechanization of sugar cane planting, fabricating a seedling preparation unite and performance evaluation of transplanting machine for sugar cane crop”, Ph.D. thesis Agric. Mech. Dept. Page: 34-55.

El-Nakib, A. A., et al. (1996). "Physical properties of sugar cane: their relation to mechanization. MSAE exploration of modem tech", In field of Agric. Eng. 4th Conference of Misr Society of Ag. Eng., 28 October 13(4), Page: 63-78.

Kroes, S. (1997). The cutting of sugarcane. PhD Thesis. University of Southern Queensland. (C.F.Mello, R. da C., and Harris, H., 2003).

Mahesh Bhandare, Chavan Akshay, Dhaigude Rajkumar, Gaikwad Ganesh and Jadhav Sunil, (2017). Sugarcane Bud Cutting Machine. International Engineering Research Journal (IERJ), Vol. 2. Issue 8. Page 2814-2816.

Mahmoud. W. A., (2016). Factors affecting the mechanical transplanting of main sugar crops. Ph.D. Thesis, Fac. of Agric., Al-Azhar Univ., Cairo, (Egypt). Page: 29-43.

Ragupathi. G., A., Ramesh Kumar, V. Selva Prakash, G. Sivaprakasam, and E.Thirumoorthi (2017). Design and fabrication of pneumatic sugarcane bud cutting machine. International Journal of Advanced Science and Engineering Research Volume: 2, Issue: 1. Page. $413-421$.

Rahul A. Sonawane, Jagdish R. Waybhase, Rushikesh B. Yengupatla, Shumail S. Shaikh, praveen K. Mali (2017). Design and development of sugar cane sprout cutter machine by human powered flywheel motor concept. Volume: 04 Issue: 01. Page. 119 124.

Suraj S. Magdum, Shubham Pawar, Pankaj B. Gavali (2016). "Sugarcane bud cutting machine", IJIRSE, Vol. 2, Issue 10. Page: :189-194. 


\section{تطوير آلة لتقطيع براعم قصب السكر \\ د. وائل أبوالمجد محمود' و د. عاشور عيد أبوالمعاطي'}

' مدرس - كلية الهندسة الزر اعية - جامعة الأزهر فرع أسيوط - مصر.

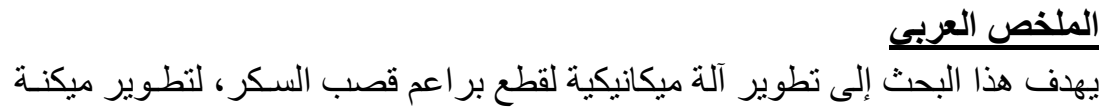

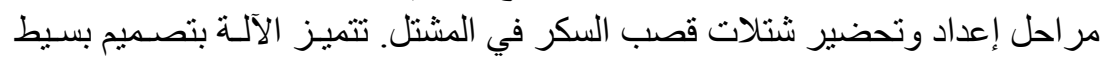

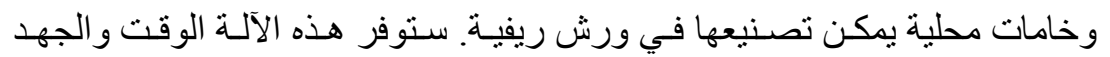

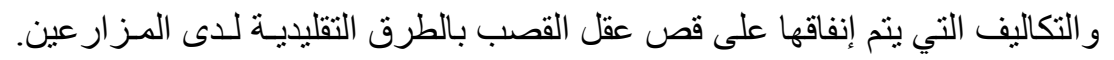

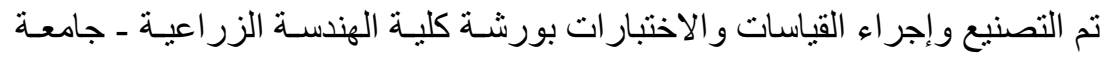

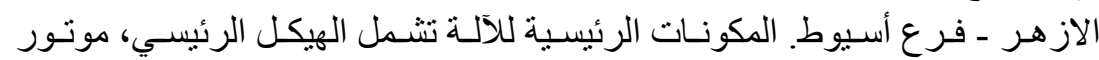
كهربي، جهاز نقل الحركة، وحدة قطع البرة البر اعم، سكاكين القطع.

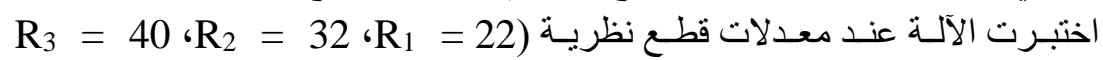

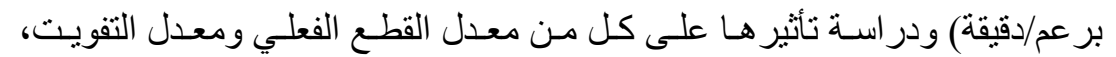

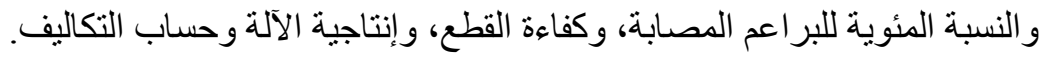

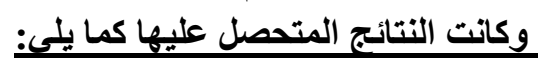

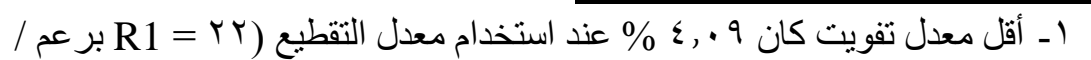

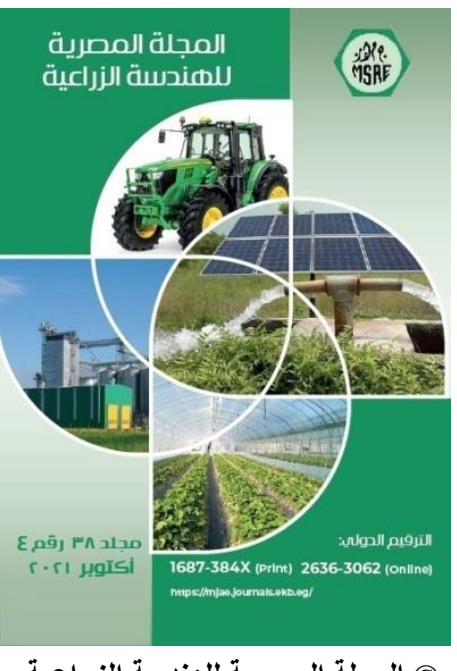

(C) المجلة المصرية للهندسة الزراعية

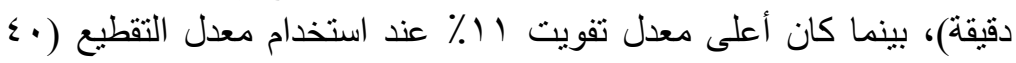

$$
\text { ( R3= بر عم / دقيقة). }
$$

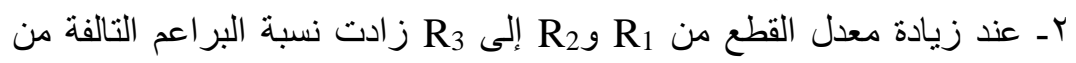

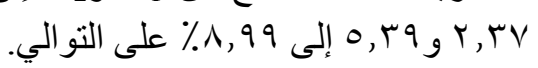

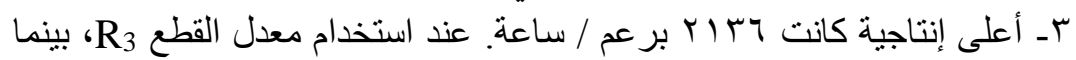

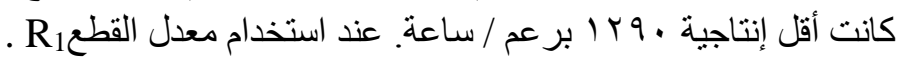

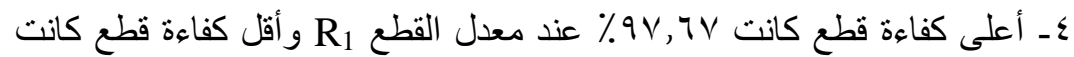

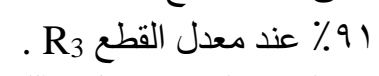

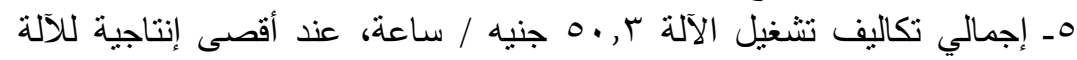

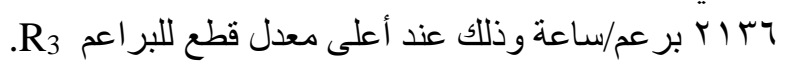

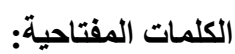

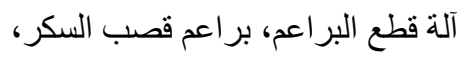

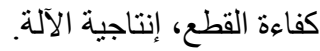

